Список литературы:

1. Пролетарский А.В., Баскаков И.В. Беспроводные сети Wi-Fi. M.: Бином, 2007.

2. Семенов Ю.А. Алгоритмы телекоммуникационных сетей. М.: Интуит, 2016.

3. Цыбаев Б.Г. Романов Б.С. Антенны-усилители. М.: Наука, 1980.

4. http://bloganten.ru

5. http://ru.wikipedia.org

\title{
Исследование вихреобразования в несжимаемых потоках в трубопроводах с использованием ПК Ansys Fluent. Картины процессов
}

\author{
Быков Р.С., студент, \\ Национальный исследовательский \\ Томский политехнический университет, \\ 2. Томск \\ E-mail: bykov.roman93@gmail.com
}

Научный руководитель: к.х.н., доцент Чухарева Н.В.

С развитием сложных современных методов исследования вихреобразования, таких как измерение скорости потока с помощью высокоскоростных вычислений и термоанемометров, визуализация потока высоких скоростей, вихревая динамика, образующаяся за телом обтекания, исследуется довольно тщательно, что приводит к множеству полезных количественных и качественных заключений.

Однако не всегда приведенные методы дают возможность всесторонне понять и изучить процесс образования вихрей. Для дополнения экспериментальных исследований в рамках данной работы проведено прямое численное моделирования рассматриваемого течения, достоверность которого подтверждается сопоставлением с данными визуализации ранее выполненных термоанемометрических измерений скорости потока и завихренности за выступом. Сочетание эксперимента и численного моделирования позволило составить ясное представление о развитии структуры отрывного течения за препятствием в канале и формировании вихревых структур.

Для составления более полной картины формирования вихревых структур в канале с цилиндрическим телом обтекания, получения количественных характеристик полей скорости и давления и их пульсаций было выполнено прямое численное моделирование исследуемого течения в пакете Ansys Fluent 13.0.

Геометрическая постановка задачи заключалась в построении плоского канала, размеры которого равны $0,7 \times 1,2$ м. Внутрь канала помещаем цилиндр, радиус которого равен $r=0,04$ м. Расположение осей цилиндра является перпендикулярным плоскости течения.

Движение потока жидкости в исследуемом канале описывается уравнением НавьеСтокса в безразмерном виде:

$$
\begin{gathered}
S \operatorname{Re} \frac{\partial U}{\partial t}+\operatorname{Re}(U, \nabla) U=-\operatorname{Re} E \nabla P+\frac{\operatorname{Re}}{F r} F+\Delta U \\
\text { где } \quad S=\frac{L}{U T}, \quad \operatorname{Re}=\frac{\rho U a}{\mu}, \quad F r=\frac{U^{2}}{g L}, \quad E=\frac{P}{\rho U^{2}} \quad \text { - числа Струхаля, }
\end{gathered}
$$


Рейнольдса, Фруда и Эйлера, соответственно;

$U, F, P$ - безразмерные скорость, потенциальная сила и давление;

$t, \nabla, \quad$ и $\Delta-$ безразмерные величины времени, операторов

дифференцирования по пространственным переменным, соответственно.

При исследовании обтекания покоящейся цилиндра радиуса $d$ потоком жидкости, который имеет на бесконечности скорость $U$, следует установить следующие граничные условия соответственно на поверхности цилиндра, а также на бесконечности:

$$
\begin{gathered}
r=d, \quad u=v=w=0, \\
r=\infty, \quad u \rightarrow U, v \rightarrow 0, w \rightarrow 0 .
\end{gathered}
$$

На поверхности цилиндра установлены условия прилипания. На нижней и верхней границах расчётной области заданы условия непротекання, при которых нормальная компоненты скорости равняется нулю.

Далее произведем качественное объяснение развития разных режимов течения в зависимости от числа Рейнольдса. Выполняется сравнение полученных результатов расчетов с картинами течения, представленных в альбоме течений жидкости и газа.

За счёт изменения скорости набегающего потока производилась вариация числа Re. Температура для среды предполагалась постоянной на протяжении всего времени. Модель турбулентности $\mathrm{k}-\omega$-SST [1] применялась для замыкания осреднённых уравнений. С целью аппроксимации производных по пространственным переменным использована конечнообъёмная MUSCL схема второго и третьего порядка аппроксимации [2]. В результате моделирования были получены все характерные режимы обтекания кругового цилиндра.

Для мальх чисел Рейнольдса $(\operatorname{Re}<1)$ обтекание кругового цилиндра считается ламинарным. Картина направлений линий тока для числа Рейнольдса равным 0.16 с трудом позволяет определить, что поток движется слева направо (рис. 1). Данный факт объясняется тем, что при числах Рейнольдса близких к единице обтекание твердого тела обратимо и, вследствие этого, симметрично при симметричной форме тела. На дополнительно приведенном рисунке распределения модуля скорости хорошо видна полученная при моделирования симметричность.

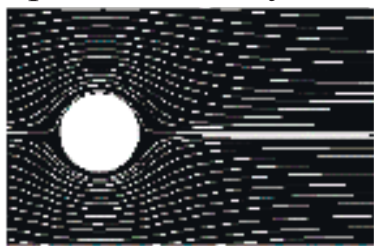

a)

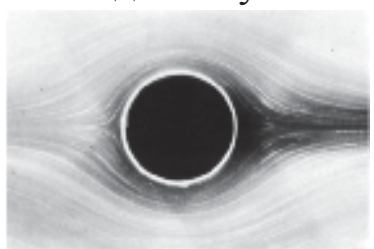

б)

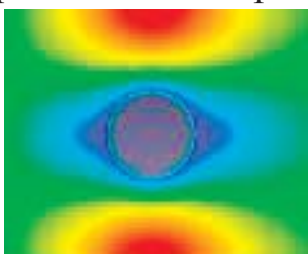

в)

Рис. 1. Мгновенные линии тока при $\operatorname{Re}=0.16(a)$, картина течения в области кругового цилиндра при $\operatorname{Re}<1$ из альбома течений жидкости и газа (б) [5], распределение модуля скорости (в)

Нарушение устойчивости ламинарного потока происходит начиная c $\operatorname{Re}=1$ и вплоть до значения $\mathrm{Re}=40$. Картина линий тока при числе Рейнольдса $\mathrm{Re}=1.54$ теряет симметрию передней и задней части, которая имела место в первом случае. Тем не менее поток все еще безотрывный, тесно прилегает к поверхности цилиндра (рис. 2). Отрыв потока примерно начинается при $\mathrm{Re}=5$, хотя значение числа Рейнольдса начала отрывного течения точно не установлено. Несимметричность распределения модуля скорости в случае моделирования хорошо видна на рисунке (рис. 2в). 


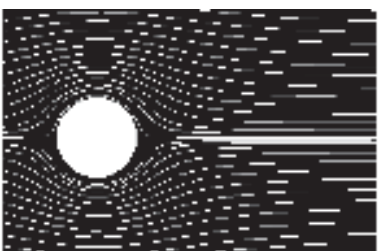

a)

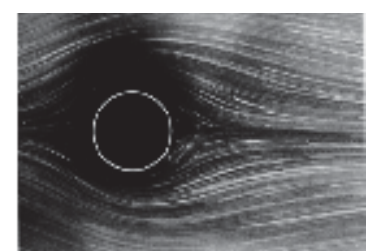

б)

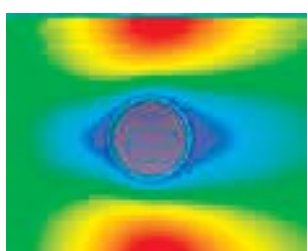

в)

Рис. 2. Мгновенные линии тока при $\operatorname{Re}=1.54(\mathrm{a})$, картина течения в области кругового цилиндра при $\operatorname{Re}<10$ из альбома течений жидкости и газа (б) [5], распределение модуля скорости (в)

Новый тип развитого вихревого течения формируется в диапазоне чисел Рейнольдса $10<\mathrm{Re}<40$. В этом случае за телом обтекания формируются два вихря, тем не менее течение остается ламинарным и стационарным. В противоположность предшествующему случаю на рисунках отчетливо видно, что произошел отрыв потока, и сформировалась пара рециркуляционных вихрей. Приближенные результаты аналогичных экспериментов в случае неограниченного потока указывают на возможность отрыва потока при $\operatorname{Re}=4 \div 5$, в то время как большая часть численных расчетов дает $\mathrm{Re}=5 \div 7$.

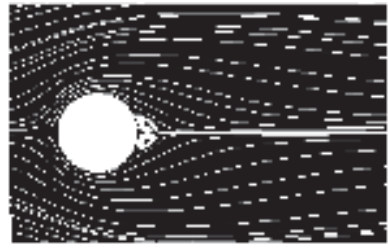

a)

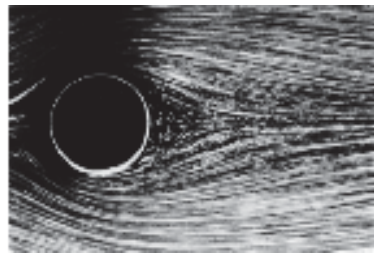

б)

Рис. 3. Мгновенные линии тока при $\mathrm{Re}=9.6$ (a), картина течения в области кругового цилиндра при $\operatorname{Re}>10$ из альбома течений жидкости и газа (б) [5]

Неподвижные вихри по мере увеличения скорости начинают вытягиваться в направлении движения потока (рис. 4). Выявлено, что их длина с ростом числа Рейнольдса линейно увеличивается, пока течение при значении Рейнольдса, превышающем 40, не станет неустойчивым. Расстояние до центров вихрей вниз по потоку в свою очередь также возрастает с увеличением числа Re. Вместе с тем поперечное расстояние между центрами вихрей увеличивается по закону, являющемуся близкому по отношению к закону квадратного корня.

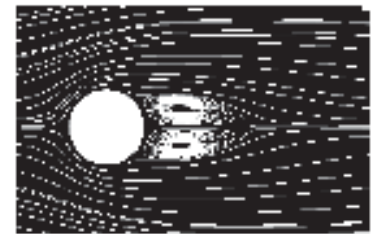

a)

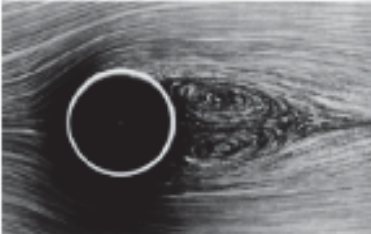

б)

Рис. 4. Мгновенные линии тока при $\operatorname{Re}=26$ (a), картина течения в области кругового цилиндра при 10 $<\operatorname{Re}<40$ из альбома течений жидкости и газа (б) [5]

Описанное выше стационарное движение с формированием в задней области течения системы из двух симметричных вихрей при условии увеличения числа Рейнольдса $(\operatorname{Re}>50)$ теряет свою устойчивость (рис. 5). В этом случае один из вихрей начинает удлиняться, отрывается и сносится по потоку жидкости вниз. Далее удлиняется и отрывается другой вихрь. 


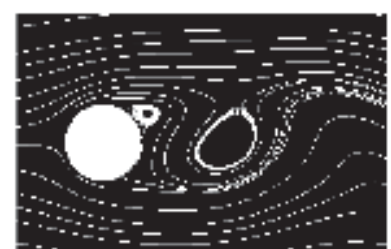

a)

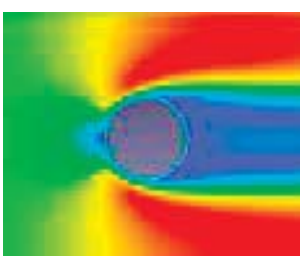

б)

Рис. 5. Мгновенные линии тока при $\mathrm{Re}=100$ (a), распределение модуля скорости (б)

На месте оторвавшихся вихрей появляются поочередно снизу и сверху новые вихри, которые также аналогичным образом отрываются от поверхности цилиндра и уносятся потоком. Возникает процесс взаимодействия отрывающихся вихрей. Данный режим неустойчивости образуется в большинстве случаев. В результате него формируется так называемая вихревая дорожка Кармана (рис. 6), движение потока становится нестационарным, но вместе с тем периодическим [6].

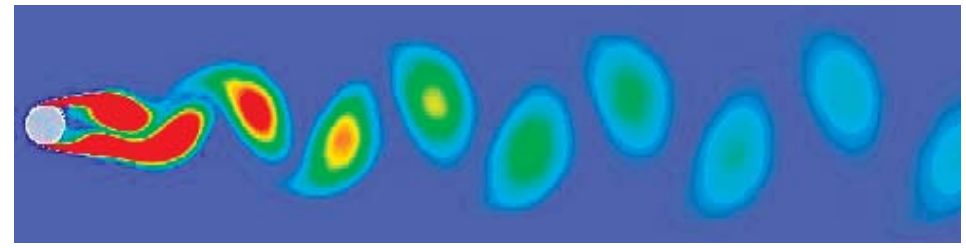

Рис. 6. Мгновенное поле завихренности при $\mathrm{Re}=1500$, полученное по расчетам c использованием SST модели турбулентности

Частота срыва вихрей обуславливается расположением точки отрыва, которая смещается от задней критической точки вверх по поверхности цилиндра с ростом скорости набегающего потока. Течение в следе и окрестности цилиндра является ламинарным при $\operatorname{Re}<150$, a прослеживание вихревой дорожки вниз по потоку возможно на расстоянии до 80d. В вихревом следе за цилиндром совершается ламинарно-турбулентный переход начиная с числа Рейнольдса близким к 150. Также область следа, в которой происходит переход с ростом Re, перемещается вверх по потоку. Начало срыва вихрей с поверхности цилиндра при $150<\operatorname{Re}<300$ происходит хаотично и установить преобладающую частоту не является возможным. Срыв вихрей становится постоянным при $\mathrm{Re}>300$ и на основную частоту накладываются турбулентные возмущения. В результате данного процесса длина вихревой дорожки уменьшается вплоть до нескольких диаметров $d$ цилиндра. Стоит отметить, что при этом число Струхаля практически остается неизменным и равняется Sh 0.21 (рис. 7).

На рисунке 7 представлена зависимость числа Струхаля от числа Рейнольдса, полученная на основе данных численного моделирования в ПК Fluent, которая показывает, что полученные в расчетах числа Струхаля хорошо согласуются с эмпирической экспериментальной зависимостью.

Ламинарно-турбулентный переход происходит в пограничном слое на поверхности цилиндра при числе Re равным $2 \cdot 10^{5}$. B результате данного процесса точка отрыва пограничного слоя смещается $к$ задней критической точке на

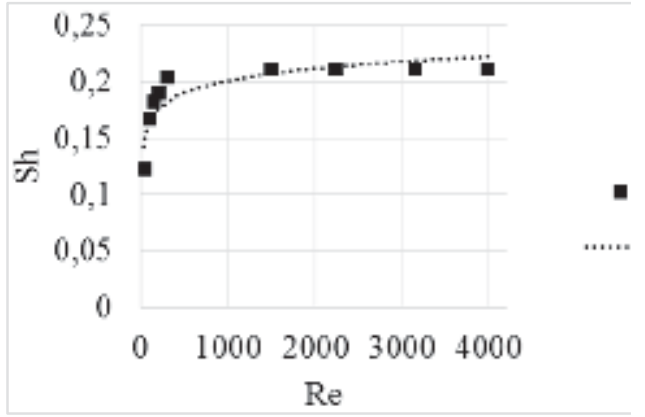

Рис. 7. Зависимость числа Струхаля от числа Рейнольдса по эмпирической зависимости (1), на основе данных численного моделирования (2) цилиндре. 
Результаты расчета сопоставлены с данными экспериментов [3, 4]. Для всех задач было получено хорошее соответствие с экспериментальными данными, что позволяет говорить о возможности применения методики расчета для исследования несжимаемых течений в окрестности плохообтекаемых тел.

\title{
Список литературы:
}

1. Menter F.R. Two-equation eddy-viscosity turbulcnco models for engineering application // AIAA J. 1994. Vol. 32, No. 8. P. 1598-1605.

2. Van Leer B. Towards the ultimate conservative difference scheme V: A second order sequel to Godunov's method // J. of Comput. Phys. 1983. Vol. 32, No. 1. P. 101-136.

3. Вальгер С.А, Фёдоров А.В., Федорова Н.Н. Моделирование несжимаемых турбулентных течений в окрестности плохообтекаемых тел с использованием ПК Ansys Fluent // Вычислительные технологии 2013 - Т. 18, № 5 - С. 27-40.

4. Вальгер С.А. Федорова Н.Н. Моделирование ветровых воздействий на конструкции в ПК Ansys // Новосибирский государственный архитектурностроительный университет (Сибстрин) - С. 73-77. 24

5. Ван-Дайк М. Альбом течений жидкости и газа. М.: Мир, 1986. - С. 184.

6. Кондранин Т.В., Ткаченко Б.К., Березникова М.В., Евдокимов А.В., Зуев А.П. Применение пакетов прикладных программ при изучении курсов механики жидкости и газа: Учебное пособие. - М.: МФТИ, 2005. - 104 с.

\section{Описание сигнатуры межпланетного магнитного поля}

\author{
Винокуров Н.А., студент, \\ Северо-Восточный федеральный университет, \\ 2. Якутск \\ E-mail: nickvnkrv@gmail.com
}

\section{Научный руководитель: о.ф.-м.н., академик РАН Крымский Г.Ф.}

Следствием дипольного характера общего магнитного поля Солнца является то, что межпланетное магнитное поле (ММП) имеет противоположную направленность в северном и южном полушарии. При этом плоскость, проходящая через солнечный экватор, разделяет области ММП противоположного направления. Эта плоскость, точнее относительно тонкий слой в окрестности этой плоскости, называется нейтральным слоем (или токовым), поскольку в этой области магнитное поле отсутствует. Поскольку плоскость солнечного экватора наклонена по отношению к плоскости эклиптики на угол, равный 7 градусам, за время одного оборота Солнца вокруг своей оси (27 суток) Земля должна дважды пересекать нейтральный слой. Каждое такое пересечение сопровождается изменением направления ММП на противоположное. Это так называемый эффект секторной структуры ММП, суть которого состоит в том, что неподвижный наблюдатель, расположенный вблизи Земли, регистрирует смену направленности ММП несколько раз за время одного оборота Солнца. По причине того, что общее магнитное поле Солнца не является чисто дипольным, а солнечный ветер не является идеально сферически симметричным, реальный нейтральный слой имеет сложную форму с отклонениями в ту и другую 